\title{
EL NUEVO MODELO GLOBAL DE COMUNICACIÓN A PARTIR DE LAS REDES SOCIALES Y TT.II.CC.
}

\section{THE NEW GLOBAL MODEL OF COMMUNICATION FROM SOCIAL NETWORKS AND TICS.}

\section{AUTOR}

\section{David Caldevilla Domínguez}

Profesor CAP 2 de la Universidad Complutense de Madrid (España)

davidcaldevilla@ccinf.ucm.es

\begin{abstract}
NOTA: La presente comunicación es fruto del desarrollo teórico que se está elaborando para la Investigación del Plan Avanza convocatoria 1/2009 del Subprograma AVANZA I+D del grupo Proyectos de investigación industrial y desarrollo experimental en cooperación: Proyectos singulares y de carácter estratégico, Proyectos tractores. Internet del futuro y otras prioridades TIC.
\end{abstract}

\section{RESUMEN}

Las Nuevas Tecnologías de la Información están trasformando la famosa Aldea global de McLuhan haciendo de ella un espacio hipertextual, en el que las Redes Sociales y la inteligencia colectiva están facilitando la interacción social, desplazando así, a los tradicionales medios de comunicación para masas a un segundo plano. No obstante el exceso de información, muchas veces incontrolado que viaja por Internet, tiene el peligro de convertirse en caldo de cultivo para la 'infoxicación', la mala-información, la desinformación y los rumores. El presente artículo pretende plantear una relectura del modelo de Comunicación Global a través de los beneficios y los peligros que conlleva la democratización de la información dentro de las Nuevas Tecnologías de la Información (TT.II.CC.). 


\section{PALABRAS CLAVE}

Globalización - TTIICC - Infoxicación - Comunicación Social

\section{ABSTRACT}

New information technologies are changing the famous McLughan's global village making it an hipertextual space, in which Social Networks and collective intelligence are making social interaction easy, thereby moving traditional mass media into background. However, the information overload, often uncontrolled found on the web, has the danger of becoming the breeding ground for intoxication, disinformation, misinformation and rumors. This article tries to reconsider the model of Global Communication through the benefits and dangers of democratization of information on New Information Technologies (NIT).

\section{KEY WORDS}

Globalization - NIT - Infoxication - Social Communication.

\section{ÍNDICE}

1. Introducción

2. La comunicación social como vehículo global: de la democracia mediática a la democracia hipertextual.

3. La globalización del receptor de información y la mundialización de los medios.

4. La cultura de masas como aparato de integración global.

5. Los pecados de la globalización de información: desinformación e 'infoxicación'.

6. Sobreinformación, Veracidad y Verdad: Un problema global

6.1. El problema de la veracidad y la Teoría del Rumor.

7. Una paradoja: El triunfo de lo local en el mundo global. 
8. Inteligencia Colectiva y Redes sociales: La Aldea global de McLuhan aplicada a las TT.II.CC.

9. Bibliografía

\section{Introducción}

Vivimos en un mundo globalizado. Esto es incuestionable. Fruto de ello es la facilidad de interacción con cualquier persona situada en el otro extremo del planeta en tan sólo unos segundos, la recepción de noticias casi al instante de producirse, la facilidad para transmitir información ubicuamente, el intercambio de papeles entre emisor y receptor en la comunicación bidireccional y multipuntual y la posibilidad del libre acceso a las fuentes de información sin intermediarios. Esta novedad derivada de la opulencia comunicativa ¿Supone la necesidad de un nuevo lenguaje para un nuevo (multi)escenario?. Está claro que sí tanto a nivel del lenguaje como de las formas (Chatman, 1990)

No obstante, la Globalización no es un descubrimiento reciente, sino que ha sido muy ampliamente estudiado a lo largo de la historia en sus diversas facetas (mundo cultural, económico, tecnológico...). Desde el mundo mercantil, el neopositivismo económico lanza años ha sus recetas mundiales para adaptar una economía local a la libre competencia mundial (Samuelson, 2006) e incluso desde la ideología contraria, hallamos los movimientos antiglobalización que pretenden hacer oír la voz de las minorías. En este marco de situación (para luego ahondar en sus aplicaciones) es en el que hemos de ubicar el concepto, por otra parte muy en boga dentro del ámbito comunicacional, de globalización. Es el 'uno para todos y todos para uno' aplicado a través de los medios tecnológicos a los escenarios informativos que pugnan por 
influir en los públicos de cualquier parte, en cualquier momento y mediante cualesquiera herramientas.

El embrión de la globalización no es otro que la Red de redes. Sin ella, este fenómeno se restringiría a los mercados continuos del capital o a las emisiones 24 horas radio-televisivas.

Las globalizaciones históricas que bien señaló Braudel en su obra Las civilizaciones actuales fueron: la Fenicia antigua, Cartago, Roma, la Europa cristiana, el Islam, Moscovia, China e India. Estas globalizaciones, que adoptan también la forma de imperios, en un comienzo se presentaron como construcciones esencialmente políticas (Braudel, 1991).

El caso de Roma, no obstante, fue especial. Existía un sentimiento popular y un proyecto de expansión del dominio sobre el conjunto del mundo civilizado. Es la primera vez en que se manifiesta una verdadera intención globalizadora, mostrándose como el gobierno de la ecúmene resultante. El Capitolio se erigía en el medio de la Ciudad que se hallaba ubicada en el centro de la Tierra, para dirigir el Orbe porque este era el destino que los Dioses les deparaban. Caso similar a los actuales EE.UU. y su Capitolio -identidad de nombre, identidad de cosmovisión-.

Por otra parte, Braudel habla también de globalizaciones parciales, y cita como ejemplo la Hansa (agrupación en la Edad Media de ciudades y corporaciones de la Europa del Norte) ya que ésta se basaba en una forma de hacer y entender el comercio con cánones comúnmente aceptados por todos sus miembros, pero que sólo se circunscribían a ese contexto.

Podemos decir, gracias a estos ejemplos, que el fenómeno de la globalización tiende a tejer redes y a apoyarse en ellas, implicando por tanto un desarrollo y una 
conquista espacial y social. Incluso yendo más allá, el concepto de superestructura ideológico-moral-religiosa derivaría de sus reglas de juego.

El gran logro de la globalización es la multidireccionalidad. Esta tendencia es estimulada sin duda por el progreso de las técnicas y los instrumentos al servicio de la información, así como la evolución en los medios de comunicación para masas (o MCM).

El presente artículo estudia diacrónicamente los fenómenos de la globalización asociados al concepto de comunicación global y aplicados por tanto, a los medios de comunicación actuales, con el fin de observar qué papel ocupan las TT.II.CC. (Tecnologías de la Información y la Comunicación) y las nuevas Redes Sociales en la evolución de la sociedad globalizada ya que éstas son causa y, a su vez, efecto de la sociedad global.

\section{La comunicación social como vehículo global: de la democracia mediática a la democracia hipertextual.}

Marshal Mcluhan es considerado mundialmente como padre del concepto de globalización comunicativa. En su concepto "Aldea Global" (1971) se aventuró a definir el futuro del mundo como una Pangea social:

"Ahora todos vivimos en este mundo irracional, instantáneo, inmediato. Yo nombré a esto la Aldea Global, pero la gente pensó que yo estaba imaginando una situación ideal. En realidad, una aldea no es una cosa ideal, porque la gente sabe demasiado sobre los demás. No hay privacidad, no hay identidad. En la Aldea Global eléctrica la gente sabe demasiado, y ya no hay un lugar donde esconderse". (McLuhan, 1971) 
El G-7 (hoy G-8 al sumarse la Rusia Exsoviética), que reúne a los países más poderosos económicamente del mundo (Canadá, Estados Unidos, Alemania, Japón, Reino Unido, Francia e Italia) acuñó en febrero de 1995 el término Sociedad Global de la Información ${ }^{1}$, que análogamente se asocia al de Globalización, en cuanto a que las nuevas TT.II.CC. conforman un factor determinante para establecer las relaciones constituyentes de la Aldea Global de McLuhan y que se vería matizada por opiniones tan preclaras como la de la profesora Fernández-Fígares: "partiendo de la base de que Globalización no es internacionalización y que la información es la principal baza del capitalismo para globalizar sus rendimientos" (Fernández Fígares, 1996).

Es por ello por lo que la globalización, lato sensu, forma un compendio o cruce de caminos, entre la información, la comunicación, la sociedad y la tecnología, matizando sus relaciones en nuevos lenguajes y contenidos transmitidos a la velocidad de la luz.

Es frecuente oír hablar de un "mundo global" interconectado. Indudablemente el desarrollo de Internet no hubiese sido posible sin la aceptación de medidas que conciernen a la llamada "nueva economía" informacional y global. En palabras de Manuel Castells "la productividad y la competitividad se generan por una red global de interacción", en estas condiciones históricas "el desarrollo en la actualidad es el conocimiento que se genera como principal fuente de productividad". (Castels 1999). De manera que el siglo XXI ha comenzado con una nueva clase de cultura

\footnotetext{
${ }^{1}$ Informe Bangermann: “Europa y la sociedad global de la información: Recomendaciones al Consejo Europeo". Bruselas, 26 de mayo de 1994.

"En todo el mundo, las tecnologías de la información y las comunicaciones están generando una nueva revolución industrial que ya puede considerarse tan importante y profunda como sus predecesoras. Es una revolución basada en la información, la cual es en sí misma expresión del conocimiento humano. Hoy en día, el progreso tecnológico nos permite procesar, almacenar, recuperar y comunicar información en cualquiera de sus formas -oral, escrita o visual-, con independencia de la distancia, el tiempo y el volumen".
}

Disponible en www.europarl.europa.eu/sides/getDoc.do?pubRef=-//EP//TEXT+REPORT+A4-1996-0244+0+DOC+XML+V0//ES 
material, producto de un nuevo paradigma especializado que se organiza alrededor a las tecnologías de la comunicación y la información, (las famosas TT.II.CC.).

Las redes de comunicación en línea, desarrolladas como parte de ese proceso global, comprenden varias funciones que influyen en el mundo que nos rodea. Así, el intercambio de mercaderías más allá de sus aranceles y servicios; la amalgama de nuevas culturas sociales; el aprovechamiento y la conciliación a nuevos contextos y la velocidad con que se transfieren recursos e intercambios que hacen del mundo una sola cosa, es decir, una sola Aldea.

Se suele caracterizar la globalización por una serie de elementos que la favorecen:

- Mayor intensidad en los flujos comerciales y de capitales internacionales;

- Desregularización económica pero también de las relaciones sociales y políticas por parte del Estado.

- Una mayor presencia de las grandes corporaciones trasnacionales y la intervención de esas corporaciones como agentes sustanciales en el nuevo mundo que ya no conforman los pueblos, ni los estados, sino empresas que eliminan las fronteras con sus productos, servicios y mensajes perturbando las culturas tradicionales de los enclaves regionales.

- Relectura de las formas políticas haciendo hincapié en la preocupación por el establecimiento de democracias liberales capitalistas.

Estos cambios y paradigmas que acarreó inicialmente la globalización no serían posibles sin la existencia y evolución de los actuales medios de comunicación y el comienzo de lo que Daniel Bell en 1970 denominó la "Sociedad de la Información" Con esta denominación se pretendió pasar de la sociedad derivada de la Revolución Industrial a un nuevo entorno humano donde la propagación y creación del conocimiento fueran los elementos más valiosos entre las naciones y los individuos.

\footnotetext{
${ }^{2}$ Disponible en www.infoamerica.org/teoria/bell1.htm.
} 
El concepto 'sociedad de la información' comprende, por tanto, el esfuerzo por transformar la información en conocimiento.

Otros elementos que distinguen a esta sociedad informacional son la velocidad con la que la información se genera, se trasmite y se procesa por un lado y la tendencia a la descentralización espacial por otro, correspondiéndole, a tal efecto, la propagación de mensajes (tradicionales 0 híper-textuales ${ }^{3}$ ) a las Redes de comunicación organizadas a través de Internet.

Uno de los frutos de esta nueva sociedad es el de la Comunicación Global por encima de la información, ya que los soportes interactúan entre sí con las ventajas que proporcionan las nuevas tecnologías y la sociedad en red. Por lo tanto, los mecanismos de retroalimentación se han implantado de tal manera, que están modificando la propia estructura del sistema comunicacional clásico (Ilamado Modelo telégrafo o Paradigma) de H. Lasswell, en torno a los años 30 del siglo XX, (EmisorReceptor-Mensaje-Canal-Efecto), remedo del clásico, y más completo, hexámetro de Quintiliano del siglo I (Quis, quid, ubi, quibus auxiliis, cur, quomodo, quando).

Es obvio que los medios de comunicación, inmersos en una sociedad completamente cambiante, atribuyen en sus métodos una paulatina mundialización, resuelta mediante la concentración de compañías de comunicación, para así poder enfrentarse a los nuevos requerimientos del mercado mundial y a las necesidades derivadas de la adaptación a las nuevas tecnologías, al mismo ritmo que se adapta a los gustos y demandas de todos los sectores sociales y económicos en una personalización derivada de las exigencias de la nueva mercadotecnia (Solano Santos, 2008).

\footnotetext{
${ }^{3}$ Podemos considerar al hipertexto como la denominación que recibe el texto que conduce a otro relacionado, en la pantalla de un dispositivo digital.
} 
Los medios se apropian de la nueva corriente ideológica de la información (ahora ya explícitamente para las masas), fundamentada en producir y recibir información de manera libre, plural, variada e incluso gratuita. Se trasmuta la denominada "democracia mediática", en la que los mediadores entre los sectores políticos y sociales son los propios medios (McLuhan en su El Medio es el masaje (1967), repasa, teóricamente, la recopilación de las fórmulas de emisión y recepción bajo el prisma de la intencionalidad, inherente a la comunicación para masas), por la "democracia electrónica" en la que cualquiera puede ser emisor y receptor, y viceversa, de información.

Un nuevo escenario es planteado. Históricamente, todos los estados han intentado controlar los medios de comunicación para masas. La censura ha sido una constante legal en todos los países y épocas. Internet supone una necesidad de releer el papel del Estado en el campo de la comunicación ya que ninguno renunciará a controlar quién dice qué a quiénes.

Este hecho está causando una profunda crisis en el papel de mediadores sociales desempeñado por los medios en el pasado y en el empuje transmitido a unos valores omnímodos mediante unos medios dominantes con apoyo de los Estados. En una relectura del concepto llegaríamos a actualizar el concepto marxista de súperestructura.

Por el contrario, se produce una paradoja tecnológica: para que la economía global sea beneficiosa se deben descentralizar las operaciones. Aquellos que creen que los flujos centrípetos se causan en una única trayectoria globalizadora sufren consecuencias sorprendentes ya que los entornos locales, nacionales e internacionales se afilian, pasándose así, del saber general a los saberes agrupados, divididos, segmentados y especializados. 
Estamos, por tanto, ante dos corrientes globalizantes. En primer lugar la globalización de la información a nivel receptor: cualquier usuario gracias a las nuevas tecnologías puede recibir información y gracias a la retroalimentación que permiten las TT.II.CC. (Tecnologías de la Información y la Comunicación) puede generar información de manera casi instantánea. En segundo lugar la globalización del formato: Los avances tecnológicos han permitido la democratización del proceso de creación en el que la tecnología se abarata, se simplifica y es accesible en su manejo para un número muy elevado de usuarios que se convierten en informadores activos. La información ya no sólo se basa en compartimentos estancos: audio, vídeo o texto. La tendencia es el aglutinamiento de los tres y la apertura a nuevas formas como las RSS (Really Simple Syndication o Agregación muy sencilla), cuyos mayores exponentes son: las bitácoras, las Redes sociales, los foros... todo lo llamado 2.0 e incluso el incipiente 3.0 tecnológico.

Como bien señala J oyanes:

"Tras la era digital (sociedad de la post-información) que viviremos en el próximo milenio será más descentralizadora, globalizadora, armonizadora y permisiva. El cambio tecnológico auspiciado por las TT.II.CC. hará realidad -al menos en teoría- la utopía de la aldea global - una nueva humanidad sin fronteras- no sin afrontar graves riesgos, lo que conllevará estar preparado técnica y culturalmente ante los nuevos retos de la cibersociedad o nueva sociedad de la información del siglo XXI." (J oyanes Aguilar, 2000) 


\title{
3. La globalización del receptor de información y la mundialización de los medios.
}

La tecnología actual permite al usuario acceder a Internet desde cualquier punto del planeta. El último avance es el wifi o línea inalámbrica que libera físicamente al usuario de un punto físico o material de enganche a la Red. Los medios de comunicación lo saben y por ello están adaptándose a esta nueva realidad rápidamente.

\begin{abstract}
"Las TT.II.CC. y sus productos de alta tecnología -hardware y software, «aparataje y programación»- son los productos y los símbolos de una nueva economía, la economía de la información. La economía de la información como señalan Castells y Hall, ha pasado más inadvertida que la economía industrial a la cual está reemplazando; aunque el advenimiento de lo que luego se ha comenzado a denominar "economía digital" ha hecho florecer una nueva economía de servicios y -naturalmente- de la información" (J oyanes Aguilar, 2000)
\end{abstract}

Después de más de una década desde la publicación de las primeras informaciones periodísticas en Internet como bien señala Martín, ${ }^{4}$ sigue siendo el perfeccionamiento de los modelos narrativos adaptados al ambiente descentralizado y no jerárquico de las redes electrónicas, uno de los principales retos de los medios comunicativos digitales. El paradigma narrativo necesita cultivar mejor las contingencias de la creación digital. Una de las operaciones más importantes del

\footnotetext{
4 “El primer diario español que apareció en Internet fue el Avui. El día fue el 1 de abril de 1995. Supone un menor coste que la edición impresa ya que los diarios en papel gastan un 55\% de su presupuesto en reproducción y distribución. De esta cifra, casi la mitad correspondería a gastos" en MARTín, María Antonia (2003): "Políticas de comunicación en la España multimedia" en Revista Historia y Comunicación Social. Número 8, pág. 203.
} 
sistema de producción ha surgido en la cultura en línea al universalizarlas. (Machado: 2000; Manovich: 2001, pág. 140 y Mielniczuck: 2003).

La información digital permite una ruptura con la escritura narrativa que yuxtapone contenidos de los medios convencionales porque favorece la combinación de elementos de varios tipos: vídeos, audios, imágenes o modelos fijos o animados en 3-D. Mientras los medios de comunicación tradicionales trabajan de forma lineal (emisor-receptor), la razón estructural en el laberinto digital actúa en torno a nodos retroalimentados y en constante perfeccionamiento con enlaces exponenciales. Es decir, múltiples emisores para múltiples receptores interconectados entre sí.

Las posibilidades en la lectura que nos ofrece la Red han roto el sistema de lectura lineal-horizontal (marcado absolutamente por el emisor) para permitirnos, como receptores, 'navegar' generando, como receptores, nosotros mismos el camino, a la par que 'leemos' el mensaje.

A partir de que Marshall McLuhan, ya en 1971, profetizara que "una red de ordenadores hará accesible, en algunos minutos, cualquier conocimiento a los estudiantes del mundo entero" (McLuhan, 1971), entendemos la necesidad de modular (una estructura en forma de red que une varios módulos, nódulos o nodos) de la nueva comunicación. Realmente, y ahora lo sabemos, lo que hizo McLuhan fue adelantarse a lo que hoy es Internet. Su famosa Aldea Global se ha quedado pequeña en nuestro aquí y ahora. El problema surge al plantearnos la imagen del nuevo 'marginado digital', pues la Red ha dejado fuera a millones de habitantes que carecen de acceso a las TT.II.CC., bien sea por motivos económicos, por habitar en zonas de "sombra electromagnética" o por situarse en una franja de edad o población en la que la utilización de las nuevas tecnologías supone unas aptitudes por encima de sus posibilidades. 
En 1998 había 147 millones de internautas en el mundo, de los cuales sólo 33 millones estaban en Europa, y ya, en el año 2008, esta tecnología sirve a más de 1.215 .000 .000 de usuarios ${ }^{5}$. Este dato sorprende incluso a visionarios tan optimistas como Nicholas Negroponte quien predijo hacia 1995 que el número de internautas en 2050 llegaría a los 1.000 millones.

No obstante, la conexión a Internet ya no está asociada únicamente a las pantallas de ordenador (sobremesa o portátil). La tendencia actual es la llamada "pantalla única" la indexación de todo tipo de información y formato dentro de una sola pantalla: las nuevas tecnologías desarrollan pantallas de teléfono móvil multifunción, desplazando a los ordenadores y al Internet tradicional. Nos acercamos rápidamente a una era donde el 3.0 y la interacción con las TT.II.CC. imperen dentro de la información global como bien señala Sánchez Carballido:

"Desde la perspectiva tecnológica de las operadoras de telecomunicaciones, responsables de construir y gestionar los soportes físicos y redes necesarios para la transmisión de señales multimedia a su través, la Convergencia se conjuga fundamentalmente en términos de la integración de servicios Triple Play (3P: voz, datos-Internet y televisión), y Cuádruple Play (4P: que incorpora al conjunto las prestaciones de la telefonía móvil)." (Sánchez Carballido, 2008)

Recién acabada la primera década del siglo XXI, los investigadores debemos hacer frente a diversos desafíos en el estudio de la 'comunicación global'.

El punto de vista pesimista de expertos como Philippe Quéau, Asdrad Torres o Eduardo Galeano (Ramonet, 1958) no deben hacernos olvidar que, en sí mismas, las

\footnotetext{
${ }^{5}$ FRANQUET, Rosa: “El cambio de rol del comunicador". Conferencia en Euroconference 99. Salamanca. 1999.
} 
nuevas tecnologías de la comunicación también aportan múltiples ventajas que deben ser consideradas. Así, frente a su teoría de la desinformación como

"la situación en la que, por incumplimiento de las normas lingüísticas y/o profesionales, el destinatario de la información recibe un producto informativo incorrecto a consecuencia del silencio, la intencionalidad o el error de la fuente, del periodista o del emisor, 0 de su interrelación". (Rivas Toitiño, 1995)

podemos contraponer positivamente el hecho de que los nuevos formatos y nuevos creadores-receptores son los protagonistas de la comunicación del siglo XXI, democratizando ad infinitum el derecho a la información libre y veraz. Aunque con reservas sobre la buena fe de algunas de las fuentes y su maridaje con la verdad.

\section{La cultura de masas como aparato de integración global}

Como señala Habermas, la teoría de la Cultura de Masas estudia los fenómenos de la integración social a través de los modernos medios de comunicación. Los medios de comunicación para masas constituyen el refuerzo técnico aportado a la narrativa comunicacional, salvando distancias en tiempo y espacio y multiplican las opciones de comunicación que atesora la red de acción informativa pero sin desligarse de las disposiciones de los plexos globales (Habermas 1998: 473).

El filósofo alemán recuerda el análisis de Horkheimer y Adorno: los flujos de información sustituyen a las estructuras de comunicación que antes habían hecho viable el debate público. Los medios audiovisuales: cine, radio y televisión, se presentan como aparatos que influyen enormemente en el lenguaje comunicativo cotidiano. 
J. Habermas defiende que los medios de comunicación liberan los procesos de comunicación de la perspectiva que suponen los contextos limitados en el espacio y en el tiempo, y virtualmente hacen surgir espacios de opinión pública, implantando la simultaneidad abstracta de una red siempre presente con contenidos muy alejados en el tiempo y en el espacio, y ofreciendo los mensajes a la disposición de cualquier usuario global presente y futuro.

\section{Los pecados de la globalización de información: desinformación e 'infoxicación'}

Se ha argüido que el pecado de la información es la desinformación, incluyendo el perfil de la que viene derivada por el exceso: la 'infoxicación'. Este término acuñado por el pensador español Alfons Cornellá hace referencia a la "intoxicación por exceso de información por falta de tiempo para digerir (metabolizar) toda la información recibida" y supone un peligro para una correcta información ya que dificulta la discriminación entre lo importante y lo superfluo. Este problema creció de forma exponencial desde la aparición de las bitácoras como fenómeno emergente hace algo más de una década y cuyo uso ha sufrido una evolución inflacionada en los últimos cinco años.

Un weblog o blog, o bitácora ${ }^{6}$ es un cuaderno de anotaciones en Internet sobre uno o varios temas y con una serie de características: actualización, organización, conversación, simplificación y distribución:

\footnotetext{
6 TIRAdo SERRANO, Francisco, y DOMENECH I ARGEMí, Miquel: Lo social y lo virtual, nuevas formas de control $y$ transformación social. Barcelona: UOC, (págs. 78-98), 2007.
}

\footnotetext{
"Para referirse a este fenómeno y a sus diferentes aspectos se han acuñado términos como el de micromedios o nano-medios, periodismo participativo (Bowman, Willis, 2003), open-source journalism (periodismo de código abierto), mass media colaborativos (Rafaeli, LaRose, 1993), etc. Una serie de conceptos y descripciones que se acercan a las elaboradas para referirse genéricamente a los fenómenos de colaboración en Internet como inteligencia colectiva (Contreras, 2003), comunidades de open-source intelligence -inteligencia de código abierto- (Stalder y Hirsch, 2002), common-based peer
} 
- Actualización porque cada cierto tiempo el autor o autores publican anotaciones, (en inglés posts).

- Organización porque estas anotaciones se encuentran clasificadas por fechas y por categorías.

- Conversación porque normalmente permite comentarios de los lectores y visitantes al sitio que fomentan el diálogo y el debate de los asuntos tratados.

- Simplificación porque es muy fácil crear, usar y publicar informaciones gracias a las bitácoras. Ya no es necesario conocer complejos lenguajes de programación para comunicar en la Red. Con esto, además, se consigue una universalización de la herramienta.

- Distribución porque puede sindicar el contenido a través de las conocidas RSS (Real Simply Sindication, en español Sindicaciones muy Simples) ya que se ofrece la posibilidad de leer las anotaciones desde un programa llamado lector o agregador de noticias sin necesidad de visitar la bitácora.

Sobre la confección de una bitácora concurren dos particularidades fundamentales: en primer lugar que los temas por tratar son libres, es decir, el autor puede hablar de lo que le plazca, ya sea con fin informativo sobre un hecho, sobre su vida personal, sobre sus creencias o sobre su punto de vista en torno a un acontecimiento; y, en segundo lugar, existe una interactividad inmediata de los lectores que generan sus respuestas a partir de los temas propuestos.

Las bitácoras, son el medio de comunicación que más ha crecido en la última década, (especialmente después del conocido 11 de septiembre del 2001, cuando sirvió de plataforma de opinión y expresión ante el terrorismo). Según los resultados del reciente informe sobre la blogosfera presentado por la reputada agencia de investigación Nielsen a través de su plataforma Blogpulse ${ }^{7}$ :

production -producción compartida entre iguales- (Benkler, 2002), creación colectiva (Casacuberta, 2003), estilo bazar (Raymond, 2000), cooking-pot markets (Ghosh, 2002) o gift economies (Rheingold, 1996; Kollock, 2003)".

7 www.blogpulse.com/ 
"En el año 2007 había poco más de 15 millones de blogs (15.534.430). En la actualidad están identificados más de 126 millones de blogs en todo el mundo y cada veinticuatro horas se abren más de 42.000 nuevos. En España, hasta el momento, se contabilizan un total de 166.000 bitácoras."

Las razones por las cuales ha cobrado tanta fuerza son muchas, pero esencialmente se trata de la fácil disposición para publicar un texto, imagen e incluso vídeos en pocos minutos y su bajo coste comparado con el constante mantenimiento que requieren ya que deben estar permanentemente actualizándose.

Las bitácoras son hoy en día un arma informativa muy importante, tanto por la retroalimentación en tiempo real que recibe la información publicada como por la libertad de expresión inherente. Desde su origen, las bitácoras han mantenido una relación muy especial con los medios de comunicación; tanta, que a día de hoy convergen con total armonía prácticamente la totalidad de los grandes medios nacionales e internacionales, integrando multitud de bitácoras en sus plataformas digitales asignándoles un gran protagonismo. Por ello también muchos periodistas 0 informadores han abierto su propio cuaderno de bitácora fuera del medio de comunicación donde colaboran asiduamente para así dar a conocer un punto de vista más personal sobre las noticias. La mayoría de los medios incluyen, desde hace poco, entre sus servicios en línea, diversas bitácoras (blogs) para dar sus noticias de forma más fresca y más cercana al lector.

\section{Sobreinformación, Veracidad y Verdad: Un problema global}

La sobreinformación no es un problema novedoso, Diderot, en su Enciclopedia en 1772 afirmaba que llegaría un momento en que sería casi imposible aprender cualquier cosa ya que cualquier fragmento de la verdad quedaría escondido en una inmensidad de volúmenes encuadernados. No se refería manifiestamente a Internet, 
puesto que era impensable entonces, y así siguió siendo hasta poco más de dos siglos después, pero sí advertía de que la sobrecarga informativa provocaría desinformación, y por tanto, alcanzar "la verdad" (aquí "información clara y veraz), sería una espinosa tarea en la que desgastar mucho tiempo y energías.

\subsection{El problema de la veracidad y la Teoría del Rumor.}

No está de más recalcar que no es lo mismo verosimilitud y veracidad. Son dos conceptos bien diferenciados que, aunque suelen coincidir en muchos de sus elementos constituyentes, no tienen necesariamente que ir de la mano. La veracidad hace referencia al grado de realismo de algo, es decir, la correspondencia de una información con su referente.

La combinación de los tres puntos confortantes de la naturaleza de la verosimilitud en la información: costumbrismo, referencias culturales y coherencia de personajes, conforma, en esencia, la base sobre la que edificar una información creíble, sea o no verdadera.

Otro de los grandes problemas de la democratización de la información (allende la infoxicación y la desinformación) consiste, por tanto, en la proliferación de información sin contrastar (también llamada 'contrainformación'). Existe una continua confusión entre la verdad de las informaciones y lo que otorga veracidad a éstas.

En el Diccionario de filosofía de José Ferrater Mora encontramos la diferencia entre verdad y veracidad en la que se lee:

"La primera tiene que ver con la realidad misma de la cosa, o la correspondencia de la cosa con el intelecto o del enunciado con aquello de que se habla etc., la segunda es una especie de correspondencia de lo que se dice con quien lo dice. Por eso 
mientras lo contrario de la verdad, o de los diversos tipos de verdad, es el error, lo contrario de la veracidad es la mentira el engaño". (Ferrater, 1979)

Muchos usuarios, y lo que es más preocupante, muchos periodistas, caen en el error de dar credibilidad a aquello que se encuentra en la Red por el mero hecho de haber sido publicado, sin molestarse en contrastarlo con otras webs o con otros medios más tradicionales (agencias de noticias, televisión, radio, prensa...), no relacionados entre sí.

Estos usuarios, que dan como cierta una información, se hacen eco de ella, ya que la emplean como fuente en su página personal, y se va creando un efecto que podemos llamar "bola de nieve", cada vez mayor, por el cual un rumor o una información falsa puede trascender por todo el planeta. Recordemos el adagio informativo, atribuido al Ministro del III Reich, Joseph Goebbels que asegura que una mentira repetida el suficiente número de veces se erige como verdad incuestionable.

Esto conlleva un gran problema e incluso trasciende a medios de comunicación para masas como televisión. Un ejemplo de ello, resultó el 5 de diciembre de 2007 la supuesta venta de Zeltia a un grupo extranjero ${ }^{8}$ lo que disparó su cotización, haciéndose eco de ello los portales bursátiles especializados.

\footnotetext{
${ }^{8}$ http://loogic.com/rumor-en-un-foro-hace-dispararse-la-cotizacion-de-zeltia-en-bolsa/
} 


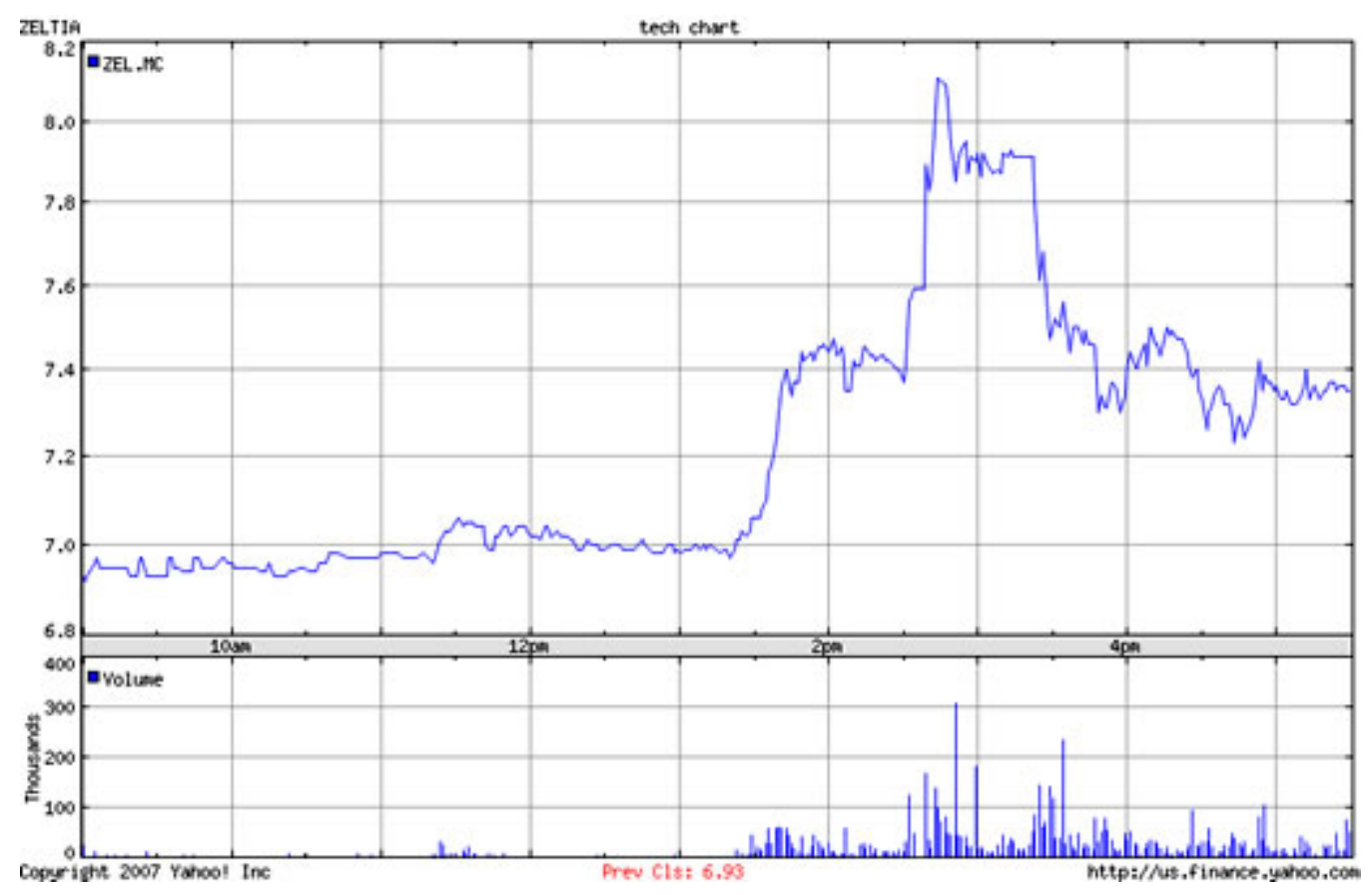

Gráfico: Ejemplo del caso Zeltia, S.A. el 5 de diciembre de 2007

Esto es sólo un ejemplo curioso de lo peligrosa que es la inexistencia de filtros en la Red y lo fácil que es la manipulación de los internautas a través de ella.

No podemos pasar por alto que la Comunicación Global facilita la proliferación de rumores. El rumor, según Allport y Postman, es una "proposición especifica para ser creída, que pasa de persona a persona generalmente por vía oral, sin medios de prueba seguros para demostrarla". (Allport y Postman, 1982)

Las Ciencias Sociales supeditan el rumor a dos características básicas:

- La ambigüedad informativa acerca de su contenido

- La trascendencia de la información.

De modo que sólo existirá el rumor si (co)existen estas dos condiciones simultáneamente. 
No obstante, en la era de la globalización, estas dos características no son suficientes. Debemos incluir en esa lista la existencia del rumor en la Red. Uno de los postulados de este nuevo lenguaje virtual es que aquello que no está en Internet, es simplemente porque no existe, de modo que la presencia en la Red es condimento básico para la credibilidad de una noticia (sea ésta un simple rumor o no). Además, por otro lado, la Red se comporta como vehículo casi instantáneo de noticias en tiempo real, y por tanto, como canalizador de rumores a nivel mundial.

\section{Una paradoja: El triunfo de lo local en el mundo global.}

En esta sociedad de información abierta por todo el mundo para todo el mundo y en todo el mundo, el problema de la 'infoxicación' y la desinformación, como hemos visto, ha hecho que las informaciones globales hayan perdido credibilidad. Eso se transforma en un interés superlativo por lo más cercano, lo local, cobrando un gran protagonismo paradójicamente.

Es por ello por lo que las Redes sociales tienen tanto éxito: los usuarios buscan gente cercana y conocida, pero con la que ya no tiene contacto. Sus compañeros de colegio, de instituto, del barrio donde se han criado, de las empresas en las que han trabajado. Es el paradigma de Frigyes Karinthy ${ }^{9}$ cuando en 1929 postuló su teoría sobre los seis grados de separación, aunque experimentos posteriores parecen no refrendar siempre este paradigma. Vivimos en un mundo global pero gracias a las TT.II.CC. queda segmentado de tal manera que, pese a su prurito universalizante, es muy factible relacionarse también con la gente más cercana.

Algo parecido sucede con los medios de comunicación convencionales. Las predicciones apocalípticas estiman que el periodismo tal y como lo conocemos hoy está a punto de desaparecer. Según el Profesor de periodismo Phillip Meyer los periódicos estadounidenses perderán en octubre de 2044 su último lector. En nuestro

\footnotetext{
${ }^{9}$ WATTS, Duncan (2003): Six Degrees: The Science of a Connected Age. W. W. NortoN. New York.
} 
país la venta de periódicos en papel ha descendido irreversiblemente y sin embargo, el periodismo local con fuerte perfil de servicio público ha evolucionado. Un ejemplo de ello son los programas de televisión del tipo "Madrileños por el mundo" (quien creó escuela autonómica), punteros en audiencia al tener como protagonista a gente común que cuenta sus vidas.

Lo local y lo personal cobran fuerza debido al gran interés que genera aquello que nos concierne directamente. Los informativos televisivos cada vez reducen más sus noticias internacionales para centrarse en las nacionales y los informativos locales están atesorando mayores cotas de audiencia.

Esta tendencia a la segmentación provincial e incluso municipal no ha pasado desapercibida para la publicidad. Las pequeñas empresas que no tienen ni el tamaño ni el presupuesto suficiente para una campaña publicitaria a nivel nacional están apostando fuerte por los medios cercanos, dada la buena respuesta del público a estos mensajes.

Pero no todas son pequeñas empresas: las grandes corporaciones han analizado que la segmentación espacial puede suponer el acercamiento a nichos de mercado mucho más prácticos, por lo que están apostando fuertemente por la geolocalización del receptor. Los teléfonos móviles y las redes sociales ofrecen a las empresas la localización de sus clientes y son éstas las que varían el mensaje dependiendo del lugar donde se encuentren consiguiendo así una penetración mucho más activa que utilizando un márketing de corte más global.

El triunfo de la cultura local supone una relectura de la comunicación por medio de los investigadores y periodistas para encontrar una nueva narrativa que se adapte a estos nuevos tiempos, ahora que cualquiera puede adoptar el papel de emisor en una competencia desleal ante los medios y profesionales de la comunicación. 
Conviene por tanto reflexionar sobre el papel del periodista digital según las palabras de Casacuberta (2004: 60-61):

"El centro de la cultura ha dejado de ser el autor, el artista, para pasar al espectador. Las obras culturales de la cultura digital ya no se construyen en forma individual, solipsista, sino de forma colectiva, organizada. El artista deja de ser creador estricto para convertirse en productor. El artista desarrolla una herramienta que luego será el público el que la use, desarrolle y difunda según sus intereses, que no tienen porque coincidir ni estar influenciados por la voluntad original del artista... El trabajo del artista es literalmente el de un médium: ofrecer una estructura, una herramienta, un medio en el que sea el espectador el que se exprese, en el que sea el espectador el que cree... poner al alcance de todo el mundo, y no sólo de los informáticos, las herramientas que permitirán nuestro desarrollo integral dentro de la sociedad de la información".

Casacuberta incide en el concepto de conocimiento global como una forma de crear la información por parte de varios autores. En relación con la creación global hallamos una figura que protagoniza directamente la nueva elaboración de elementos informacionales en los medios de comunicación en línea. Nos estamos refiriendo al concepto que Moreno acertó en llamar "lectoautor" (Moreno, 2001) como máxima expresión de un lector no sólo activo, sino partícipe del proceso narrativo. Muy al gusto de la nueva imagen protagónica del binomio actor-receptor de la obra literaria y que Umberto Eco vaticinó en su Lector in fábula (1979).

En este proceso creativo es decisiva la formación del receptor, con una forma determinada de estructurar y ordenar la realidad (Fernández Rodríguez, 2004). 
Según Lévy (2004) ${ }^{10}$, la implantación de la narrativa de producción social está siendo simplificada por las tecnologías de la información y la comunicación, las cuales están permitiendo el fortalecimiento de una llamada "inteligencia colectiva" que motiva la acción colectiva para el intercambio de ideas y las tomas de decisión y, por qué no, para la creación de noticias.

Un ejemplo de este nuevo "periodismo colectivo" también llamado "periodismo participativo", (porque cuenta con la colaboración de ciudadanos ajenos a los medios, guiados por periodistas profesionales, para sacar a la luz asuntos de interés público) lo encontramos en caso de $O h \mathrm{My} \mathrm{News}^{11}$, el veterano medio surcoreano en línea, que ya cuenta con más de 42.000 ciudadanos reporteros y 50 periodistas profesionales que forman una Red Social en la que comparten sus informaciones y experiencias que luego se vierten en el diario.

Examinado desde este punto de vista, el leitmotiv de la Red 2.0 es el caldo de cultivo de la creación colectiva. Estas aplicaciones de "segunda generación", buscan acortar (y anular) la distancia entre los que navegan por la Web y los que publican en ella información, (entre lector y periodista trazando un paralelismo).

En este estado de la cuestión encontramos proyectos de investigaciones como la que se está desarrollando para un I+D AVANZA del Ministerio de Industria para el 2009 y 2010 en el que se pretende desarrollar un programa de gestión autónoma para usuarios que pueden interactuar en plataformas comunes generando radio-clubes por Internet.

De esta manera la aportación de los expertos en comunicación se circunscribe al hecho de generar tutoriales profesionales para la confección de programas con calidad, intercambiables en estas plataformas comunes (radio-clubes en línea) y así

\footnotetext{
${ }^{10}$ http://inteligenciacolectiva.bvsalud.org.

${ }^{11}$ http://es.wikipedia.org/wiki/OhmyNews
} 
aunar el concepto receptor y generador de programas dentro de los parámetros de calidad semi-profesional que la comunicación interpersonal del futuro exige. Es una aplicación del nuevo concepto creative commons (creaciones públicas) enfocado a solventar necesidades de calidad para los nuevos lectoautores del siglo XXI. La página web del modelo beta estará disponible en breve en www.radio4friends.org. La historia ha hecho mudar el modelo económico del negocio de las comunicaciones para masas pero no su función social.

\section{Inteligencia Colectiva y Redes sociales: La Aldea global de McLuhan aplicada a las TT.II.CC.}

La verdadera revolución histórica que supone las TT.II.CC. para el posterior desarrollo colectivo de la humanidad radica en las aportaciones colectivas, en los esfuerzos comunes y, en definitiva, en la unificación de avances en una dirección predeterminada. "La inteligencia colectiva es una forma de inteligencia que surge de la colaboración y concurso de muchos individuos". Tal definición surge de los trabajos de Peter Russell (1983), Tom Atlee (1993), Pierre Lévy (1997), Howard Bloom (1995), Francis Heylighen (1995), Douglas Engelbart, Cliff Joslyn, Ron Dembo, Gottfried Mayer-Kress (2003).

Podemos tomar la Inteligencia colectiva como una inteligencia distribuida de forma ubicua, continuamente revalorizada, coordinada en tiempo real, efecto de una movilización efectiva de capacidades. Es incuestionable que nadie tiene un saber ilimitado, el secreto de la inteligencia colectiva radica en la conjunción de saberes especializados interactuando en el mismo entorno virtual de conocimientos.

El principal proyecto arquitectónico del siglo XXI es diseñar y organizar el espacio interactivo y móvil de la Red. En este espacio social, económico, científico y cultural las personas están desarrollando otras formas de lectura/escritura/producción de contenidos resultado del uso de herramientas 2.0 y las llamadas Redes Sociales. 
Las personas -antes meros internautas u observadores, es decir, simples usuariosasumen el papel de autoras y productoras de sus propios recursos, aumentando la facultad comunicativa con los demás porque se sienten parte de un gran colectivo global, de su nuevo universo de, como bien define el investigador Alvin Toffler, "prosumidores" (productores y consumidores) conectados a la Red. (Toffer, 1980).

Gracias a esta dinámica de morfogénesis, ${ }^{12}$ surgen una serie de aplicaciones basadas en el modelo de las comunidades virtuales en las cuales (a diferencia de los que se consolidaron en la primera etapa de Internet) los usuarios pasan a ser de consumidores de información a productores y gestores de sus propios contenidos, consolidando Redes Sociales desarrolladas en un lugar en el que comunicarse, intercambiar información, solventar dudas y conocimiento con otras personas.

Los propios usuarios serán los dueños de los contenidos, que obtendrán una visibilidad exponencialmente infinita y sin mediar un conocimiento tecnológico profesional para su manejo y 'colgado'. La actualización y la retroalimentación del sistema se podrán realizar en tiempo real.

Las Redes Sociales son estructuras formadas por personas, organizaciones 0 entidades, las cuales están vinculadas por uno o varios tipos de relaciones, tales como parentesco, amistad, filiaciones comunes, intereses económicos, relaciones sentimentales, creencias compartidas o que aportan su conocimiento o prestigio. Si Abraham Maxlow actualizara su archifamosa pirámide de necesidades, en el estrato

\footnotetext{
12 Navarro, Pablo (1996) en Pérez-Agote Poveda, A. y Sánchez de la Yncera, I. (eds.), Complejidad y Teoría Social, Madrid: Centro de Investigaciones Sociológicas pp. 436-465. Con este propósito, se propone la utilización de la idea de 'morfogénesis social' como concepto capaz de aunar de manera dinámica las nociones tradicionales de 'estructura social' y 'cambio social'. Después de pasar revista a algunas de las categorías básicas de la teoría sociológica, como la distinción 'micro/macro', la noción de 'morfogénesis social' se perfila por medio del concepto de 'ruptura/recomposición de simetrías agenciales'. De acuerdo con este punto de vista, y contemplados desde la perspectiva del sujeto individual, los procesos de morfogénesis social se fundamentan en la dinámica de ruptura y recomposición de las simetrías agenciales que definen a tal sujeto como agente. En la última sección del trabajo, se sugiere una extensión de este enfoque a la esfera de la interacción colectiva.
} 
más elevado de reconocimiento social habría indefectiblemente que hacer referencia a esta nueva forma social de existir, reconocer y ser reconocido.

Quizás también León Vygotski, de poder reformular su teoría sobre el aprendizaje infantil basada en la Zona de Desarrollo Próximo (ZDP), debería reservar hoy un lugar preponderante para los Medios de Comunicación para Masas y para las TT.II.CC. relacionales.

El análisis de Redes Sociales estudia esta estructura global comunicativa aplicando la Teoría de Grafos (conjunto de objetos llamados nodos unidos por una selección de vértices, llamados aristas, que pueden ser orientados o no y que los interconectan). I dentificando las entidades como "nodos" y las relaciones como "enlaces" o "aristas". La estructura del grafo puede resultar no obstante, a menudo muy compleja.

Esto conlleva consecuencialmente la destrucción de las barreras espacio-temporales entre los actores de la comunicación aboliendo lecturas lineales y centralizadas. Estos aspectos multipuntuales y multilineales pueden provocar negativamente una serie de descodificaciones aberrantes allende las intenciones primigenias de los (multi)emisores.

Si el siglo XVIII asistió a una Revolución Industrial que cambió la forma de producción, el siglo XIX a la ruptura de las relaciones sociales llamadas clásicas, el siglo XX ha supuesto el embrión de la más grande revolución que la historia verá: la tecnológica aplicada a la comunicación.

NÍHIL ÓBSTAT . IMPRIMÁTUR 


\section{Bibliografía}

ALLPORT, Gordon W. y POSTMAN, Leo (1947): The Psychology of Rumor, New York: Henry Holt; edición en español: ALLPORT, Gordon y POSTMAN, Leo (1982): La psicología del rumor. Editorial Psique. Buenos Aires.

BRAUDEL, Fernand (1991): Las civilizaciones actuales. Estudio de la historia económica y social. Rei. México.

CALDEVILLA DOMínGUEZ, David (2004): Relaciones Públicas y su fundamentación. Vision Net. Madrid.

CASACUBERTA, David (2003): Creación colectiva. En Internet el creador es el público. Gedisa. Barcelona.

CASTELLS, Manuel (1997): “Globalización, tecnología, trabajo, empleo y empresa" en Revista La Factoría no 7 octubre 1997. Disponible en: www.lafactoriaweb.com/articulos/castells7.htm\# (Consultado el 22 de febrero de 2008).

CHATMAN, Seymour (1990): Historia y discurso. La estructura narrativa en la novela y en el Cine. Taurus. Madrid.

FRANQUET, Rosa (1999): "El cambio de rol del comunicador". Conferencia en Euroconference 99. Salamanca.

HABERMAS, Jürgen (1998): “Modernidad: un proyecto incompleto". Revista Punto de Vista. no 21. Buenos Aires. 
INFORME BANGERMANN (1994): “Europa y la sociedad global de la información: Recomendaciones al Consejo Europeo" Bruselas, 26 de mayo de 1994. Disponible en: www. europarl. europa.eu/sides/getDoc. do? pubRef=-//EP//TEXT+REPORT+A4-1996$\underline{0244+0+D O C+X M L+V 0 / / E S}$ (Consultado el 22 de febrero de 2008).

JOYANES AGUILAR, Luis (2000): "Cambio tecnológico y nueva sociedad de la información (Cibersociedad). Séptima y última parte: La revolución silenciosa y la cibersociedad." en Revista de Comunicación Vivat Academia no 16 Junio 2000. Disponible en: www2.uah.es/vivatacademia/anteriores/dieciseis/cibermaneras.htm (Consultado el 15 de diciembre de 2007).

LÉVY, Pierre (2004): Inteligencia Colectiva. Por una antropología del ciberespacio. Disponible en http://inteligenciacolectiva.bvsalud.org. (Consultado el 21 de febrero de 2008).

MACHADO, Eduardo (2002): "Géneros Narrativos en el periodismo digital baiano" en Sala de Prensa. Año 5, Vol 2, Enero 2002. Disponible en: www.saladeprensa.org/art517.htm (Consultado el 20 de febrero de 2008).

MAGUREGUI, Carina: “Wikipedia, Enciclopedia Británica, redes, inteligencia colectiva y trabajo colaborativo".

Disponible en: http://portal.educ.ar/debates/sociedad/wikipedia-enciclopediabritani.php Consultado el 16 de diciembre de 2007).

MANOVICH, Lev (2006): ¿Qué son los nuevos medios?. Paidós. Barcelona.

MCLUHAN, Marshal (1971): Guerra y paz en la aldea global. Martínez Roca. Barcelona. 
MIELNICZUK, Luciana (2003): Periodismo en la red: Una contribución para el estudio del formato de la noticia en la narrativa hipertextual. Tesis en Comunicación. Universidad Federal de Bahía (Brasil).

MORENO, Isidro (2001): "Genoma digital" en Revista Anàlisi, no 27, pág. 101-114. Disponible en www.bib.uab.es/pub/analisi/021121 75n27p101.pdf (Consultado el 20 de febrero de 2008).

NAVARRO, Pablo (1996) en Pérez-Agote Poveda, A. y Sánchez de la Yncera, I. (eds.), Complejidad y Teoría Social. Centro de Investigaciones Sociológicas. Madrid.

NEGROPONTE, Nicholas (1995): El mundo digital. Ediciones B. Barcelona.

RAMONET, I. (1998): Internet, el mundo que llega. Alianza Editorial. Madrid.

RIVAS TOITIÑO, José Manuel (1995): “Desinformación, Revisión de su significado: del engaño a la falta de rigor" en Estudios sobre el mensaje periodístico, no 2, 1995.

SAMUELSON, Paul (1948): Economía: Un análisis introductorio. Madrid: McGrawHill/Interamericana de España, S.A. (18o edición 2006).

SÁNCHEZ CARBALLIDO, Juan Ramón (2008): "Vectores tecnológicos de la convergencia en el sector Info+Com" en Historia y comunicación social, nํ 13, 2008.

SOLANO SANTOS, Luis Felipe (2008): Patrocinio y Mecenazgo: instrumentos de responsabilidad social corporativa. Fragua Comunicación. Madrid.

TIRADO SERRANO, Francisco y DOMENECH I ARGEMÍ, Miquel (2007): Lo social y lo virtual, nuevas formas de control y transformación social. Barcelona. UOC. 
TOFFLER, Alvin (1980): The Third Wave. Bantam Books. Londres

WATTS, Duncan (2003): Six Degrees: The Science of a Connected Age. W.W. Norton. Nueva York. 